\title{
Kinetic and Mechanism of Oxidation of Benzazolylformamidines by Permanganate in Alkaline Medium
}

\author{
Ahmed Fawzy $^{1,2}$, *, Ishaq Zaafarany ${ }^{1}$, Ismail Althagafi ${ }^{1}$, Ameena Al-Bonayan ${ }^{1}$, Faten Aljiffrey ${ }^{1}$ \\ ${ }^{1}$ Chemistry Department, Faculty of Applied Science, Umm Al-Qura University, Makkah, Saudi Arabia \\ ${ }^{2}$ Chemistry Department, Faculty of Science, Assiut University, Assiut, Egypt
}

Email address:

afsaad13@yahoo.com (A. Fawzy), iazaafarany@uqu.edu.sa (I. Zaafarany), iithagafi@uqu.edu.sa (I. Althagafi), benayana@hotmail.com (A. Al-Benayan), fateng25@hotmail.com (F. Aljiffrey)

${ }^{*}$ Corresponding author

\section{To cite this article:}

Ahmed Fawzy, Ishaq Zaafarany, Ismail Althagafi, Ameena Al-Bonayan, Faten Aljiffrey. Kinetic and Mechanism of Oxidation of Benzazolylformamidines by Permanganate in Alkaline Medium. American Journal of Applied Chemistry. Vol. 4, No. 2, 2016 , pp. 50-58. doi: $10.11648 /$ j.ajac.20160402.13

Received: February 21, 2016; Accepted: March 6, 2016; Published: March 19, 2016

\begin{abstract}
In alkaline medium, the kinetics of oxidation of two substituted benzazolylformamidines, namely $N, N$-dimethyl$N^{\prime}$-(1H-benzimidazol-2-yl) formamidine (BIF) and $N, N$-dimethyl- $N^{\prime}$-(benzthiazol-2-yl) formamidine (BTF) by permanganate ion has been studied spectrophotometrically at a constant ionic strength of $0.1 \mathrm{~mol} \mathrm{dm}{ }^{-3}$ and at $25^{\circ} \mathrm{C}$. The reactions exhibited first order kinetics with respect to [permanganate]. Fractional-first order dependences of both reactions on [reductants] and [alkali] were revealed. Increasing either ionic strength or solvent polarity of the medium had no significant effect on the rates. The final oxidation products of BIF and BTF were identified as 2-aminobenzimidazole and 2-aminobenzthiazole, respectively, in addition to dimethylamine and carbon dioxide. Under comparable experimental conditions, the oxidation rate of BIF was higher than that of BTF. The reaction mechanism adequately describing the kinetic results was proposed, and the reaction constants involved in the different steps of the mechanism have been evaluated. The activation parameters with respect to the rate-limiting step of the reactions, along with thermodynamic quantities were computed and discussed.
\end{abstract}

Keywords: Permanganate, Oxidation, Benzazolylformamidines, Kinetics, Mechanism

\section{Introduction}

Benzimidazole is a dicyclic compound having imidazole ring (containing two nitrogen atoms at non-adjacent positions) fused to benzene. Benzimidazole structure is a part of the nucleotide portion of vitamin $\mathrm{B}_{12}$ and the nucleus in some drugs such as proton pump inhibitors and anthelmintic agents. Benzimidazole and its derivatives are widely used as intermediates in synthesis of organic target compounds including pharmaceuticals, agrochemicals, dyes, photographic chemicals, corrosion inhibitors, epoxy curing agents, adhesives and plastic modifiers. Also, they used as vermicides or fungicides as they inhibit the action of certain microorganisms.

Benzthiazole derivatives, sulfur containing compounds, have been a topic of interest for research for over a century because they have important biological activities and have been developed for the treatment of muscle relaxants, diabetes, tuberculosis, epilepsy, analgesia, inflammation and viral infection [1-3]. They were showed inhibitory effect against human laryngocarcinoma [4], anticancer [5, 6], antitumoractivity [7], fungicidal activities [8], antihelmintic [9], antiviral [10], and antimicrobial activity [11]. The benzthiazolylformamidine derivatives reacted with heterocyclic amines to give biologically active heterocyclic compounds [12].

In the last decades, formamidine derivatives find increased interest due to their broad spectrum of biological activity. Benzimidazolyl- and benzthiazolylformamidines are noted to form complexes with different metal ions such as $\mathrm{Co}(\mathrm{II})$, $\mathrm{Cd}(\mathrm{II}), \mathrm{Cu}(\mathrm{II}), \mathrm{Fe}(\mathrm{III}), \mathrm{Ni}(\mathrm{II})$ and $\mathrm{Zn}(\mathrm{II})$ [12-14]. The $N, N$ - 
dialkyl formamidine derivatives are highly effective acaricides and the most rewarding of these studies resulted in discovery of the acaricide insecticide chlordimeform. The oxidative cleavage of formamidines is quite important, since the $N, N$-dialkyl formamidine group is one of the most versatile protecting groups, especially in biosynthetic applications.

Potassium permanganate is widely used as an oxidizing agent for many organic molecules in various media [15-25]. The mechanism of oxidation reactions by permanganate is governed by $\mathrm{pH}$ of the medium [26]. Among six oxidation states of manganese from $\mathrm{Mn}(\mathrm{II})$ to $\mathrm{Mn}(\mathrm{VII})$, permanganate, $\mathrm{Mn}$ (VII) is the most potent oxidation state in both acid and alkaline media. During oxidation by permanganate, it is evident that the $\mathrm{Mn}(\mathrm{VII})$ in permanganate is reduced to various oxidation states in acidic, alkaline and neutral media.

A literature survey revealed that there are no reports on the kinetics of oxidations of benzazolylformamidines by permanganate, or by any other oxidants. In view of the above aspects we tend to investigate the kinetics and mechanism of oxidations of two derivatives of benzazolylformamidines $(N$, $N$-dimethyl- $N$ '-(1H-benzimidazol-2-yl) formamidine (BIF) and $N, \quad N$-dimethyl- $N$ '-(benzthiazol-2-yl) formamidine (BTF)) by alkaline permanganate. The objectives of the present study are to establish the optimum conditions affecting oxidation of the benzazolylformamidines, to check the selectivity of permanganate towards such substrates and to elucidate a plausible oxidation mechanism.

\section{Experimental}

\subsection{Materials}

All chemicals employed in the present work were of analytical grade and their solutions were prepared by dissolving the requisite amounts of the samples in doubly distilled water. Fresh solutions of benzazolylformamidine derivatives were prepared as reported elsewhere [12]. The solution of potassium permanganate was freshly prepared and standardized as reported earlier [27]. Sodium hydroxide, sodium perchlorate and $t$-butyl alcohol were used to vary the alkalinity, ionic strength and dielectric constant in the reaction medium, respectively.

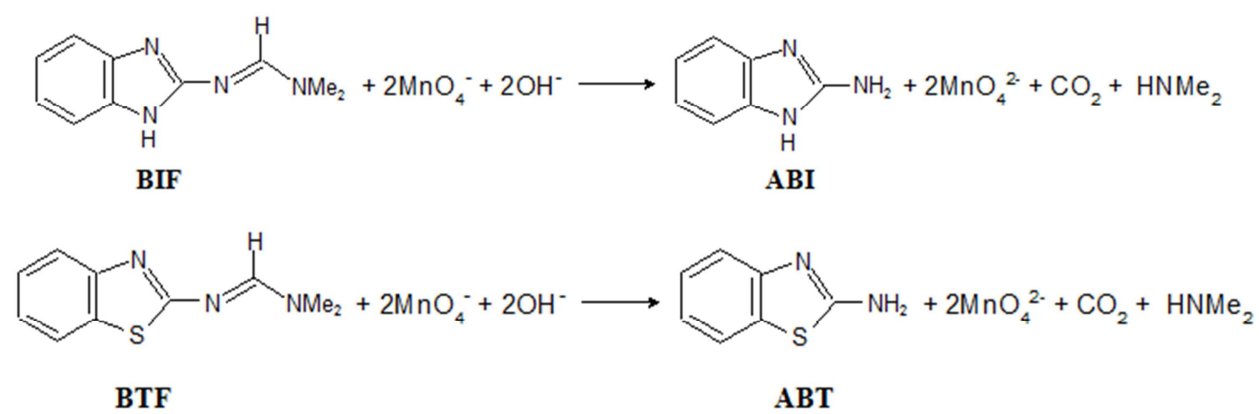

where the final oxidation products of BIF and BTF were identified as described elsewhere $[12,18-20]$ as 2-

\subsection{Kinetic Measurements}

Kinetic runs were carried out under pseudo-first order conditions where benzazolyl-formamidine substrates (abbreviated by S) are present in large excess over that of permanganate. The reactions was initiated by mixing the previously thermostatted solutions of permanganate and substrate that also contained the required amounts of $\mathrm{NaOH}$ and $\mathrm{NaClO}_{4}$. The progress of the reactions was followed up to not less than two half-lives by recording the decrease in the absorbance of permanganate as a function of time at its absorption maximum $(\lambda=525 \mathrm{~nm})$, whereas the other constituents of the reaction mixtures do not absorb significantly at this wavelength. The absorbance measurements were made in a thermostatted Shimadzu UVVIS-NIR-3600 double-beam spectrophotometer. The reactions temperature was controlled to within $\pm 0.1^{\circ} \mathrm{C}$.

First order plots of $\ln ($ absorbance) versus time were found to be straight lines up to at least $80 \%$ of the reactions completion and the observed first order rate constants $\left(k_{\text {obs }}\right)$ were calculated as the gradients of such plots. Average values of at least two independent values of the rate constants were taken for the calculation. The rate constants were reproducible to within $4 \%$. The order of reaction with respect to the reactants were determined from the slopes of the log $k_{\mathrm{obs}}$ versus $\log$ (concentration) plots by varying the concentrations of the substrate and alkali, in turn, while keeping other conditions constant.

Few kinetic runs were carried out after bubbling purified nitrogen and compared with those taken under air, and the results were found to be the same. Thus the dissolved oxygen did not have any effect on the rate constants.

\section{Results}

\subsection{Stoichiometry and Product Identification}

Reaction mixtures containing different initial concentrations of the reactants at $\left[\mathrm{OH}^{-}\right]=0.05$ and $I=0.1$ mol dm${ }^{-3}$ at $25^{\circ} \mathrm{C}$ were equilibrated in dark. The unconsumed permanganate concentration was estimated by both titrimetric and spectrophotometric techniques. The results indicate consumption of two permanganate ions for one molecule of benzazolylformamidines to yield the oxidation products as shown in the following Scheme,

ABT

aminobenzimidazole (ABI) and 2-aminobenzthiazole (ABT), respectively, in addition to dimethylamine and carbon 
dioxide. Dimethylamine was identified by a spot test [28], the intermediate $\mathrm{Mn}^{\mathrm{VI}} \mathrm{O}_{4}{ }^{2-}$ by its visible spectrum and carbon dioxide by lime water.

\subsection{Time-Resolved Spectra}

The spectral scans during the oxidation of benzazolylformamidine derivatives by alkaline permanganate are shown in Fig. 1(a, b). The Figure shows a gradual decay of the permanganate band at $\lambda=525 \mathrm{~nm}$ with a corresponding growth of new intermediate absorption maxima at wavelengths of 606 and $435 \mathrm{~nm}$ with appearance of two isosbestic points at wavelengths 575 and $473 \mathrm{~nm}$ during the courses of the reactions.
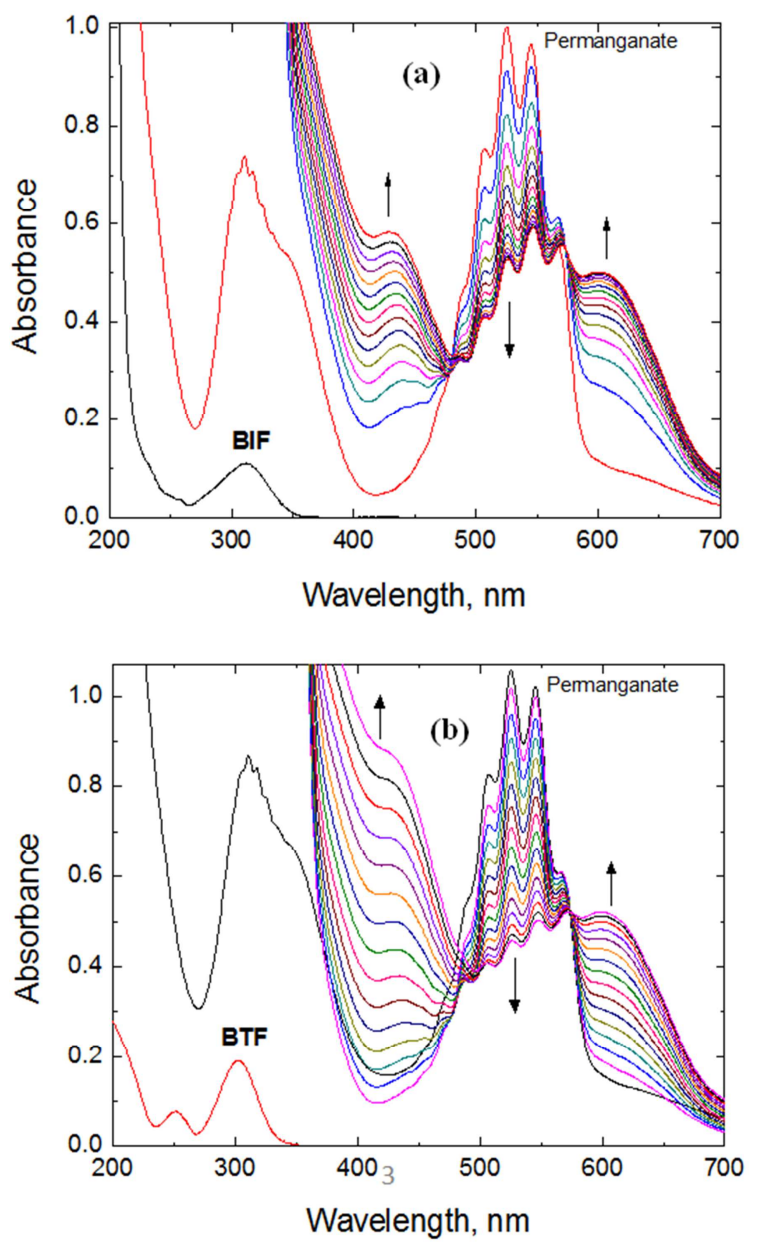

Figure 1. Spectral changes for the oxidations of benzazolylformamidines by alkaline permanganate. $[\mathrm{S}]=1.0 \times 10^{-2},\left[\mathrm{MnO}_{4}^{-}\right]=4.0 \times 10^{-4},\left[\mathrm{OH}^{-}\right]=0.05$ and $I=0.1 \mathrm{~mol} \mathrm{dm} \mathrm{m}^{-3}$ at $25^{\circ} \mathrm{C}$. Scan time intervals $=1 \mathrm{~min}$.

\subsection{Effect of Permanganate Concentration}

Permanganate oxidant was varied in the concentration range of $1.0 \times 10^{-4}$ to $8.0 \times 10^{-4} \mathrm{~mol} \mathrm{dm}^{-3}$ while other reactant concentrations were kept constant. The $\mathrm{pH}$ and temperature were also kept constant. It has been observed that plots of $\ln$ (absorbance) versus time were linear up to about $80 \%$ of the reaction completion. Furthermore, the increase in the oxidant concentration did not alter the oxidation rates (Table 1). These results indicate that the order of reactions with respect to the oxidant is confirmed to be one.

\subsection{Effect of Substrates Concentration}

The observed first order rate constants were determined at different concentrations of the reductants BIF and BTF keeping others constant. Plots of $k_{\text {obs }}$ versus [S] were found to be linear with positive intercepts on $k_{\text {obs }}$ axes (Fig. 2) confirming the fractional-first order dependences with respect to substrates concentration.

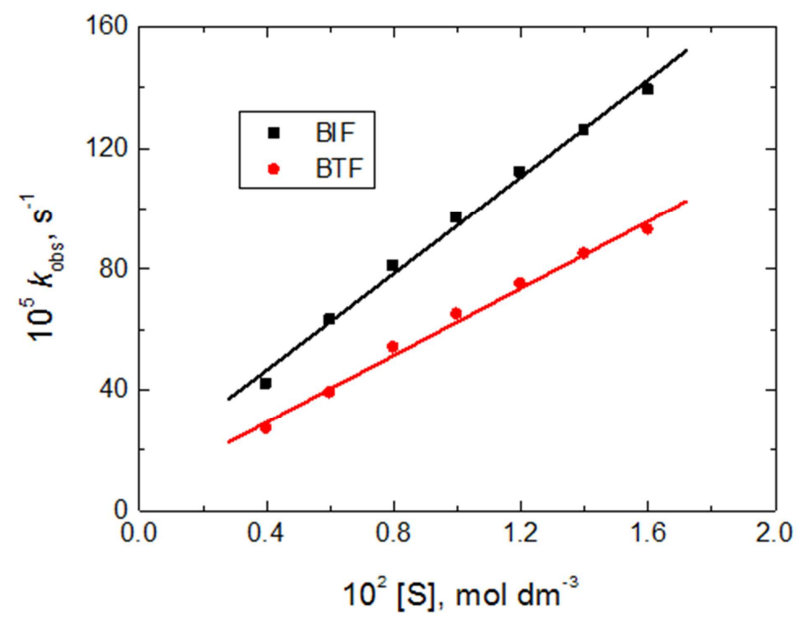

Figure 2. Plots of the observed first order rate constants $\left(k_{o b s}\right)$ versus substrate concentration [S] in the oxidations of benzazolylformamidines by alkaline permanganate. $\left[\mathrm{MnO}_{4}^{-}\right]=4.0 \times 10^{-4},\left[\mathrm{OH}^{-}\right]=0.05$ and $\mathrm{I}=0.1 \mathrm{~mol}$ $d m^{-3}$ at $25^{\circ} \mathrm{C}$.

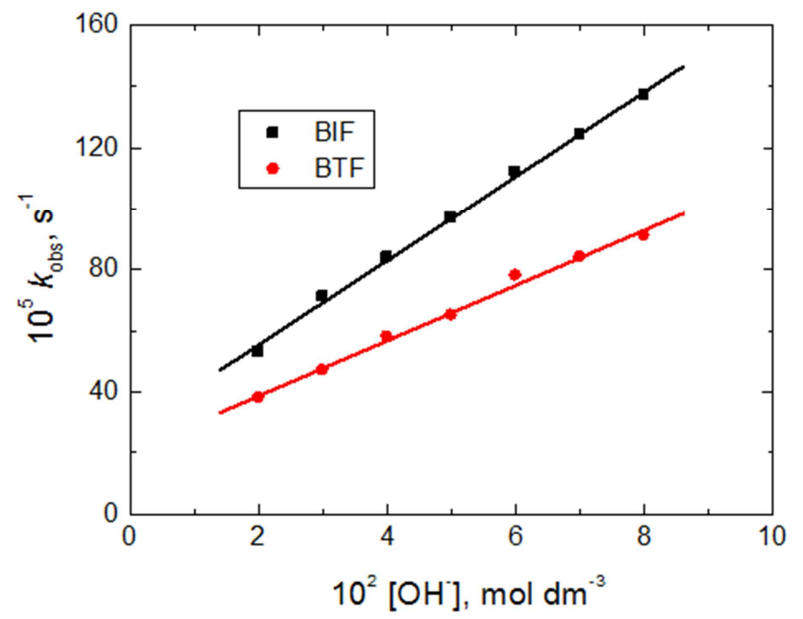

Figure 3. Plots of the observed-first order rate constants $\left(k_{\text {obs }}\right)$ versus alkali concentration in the oxidations of benzazolylformamidines by alkaline permanganate. $[\mathrm{S}]=1.0 \times 10^{-2},\left[\mathrm{MnO}_{4}^{-}\right]=4.0 \times 10^{-4}$ and $I=0.1 \mathrm{~mol} \mathrm{dm}^{-3}$ at $25^{\circ} \mathrm{C}$.

\subsection{Effect of Alkali Concentration}

The influence of alkali on the rates was studied at various $\left[\mathrm{OH}^{-}\right]$, keeping all other reactant concentrations constant. The rate constants increased with increasing alkali concentration (Table 1). Plots of $k_{\mathrm{obs}}$ versus [ $\left.\mathrm{OH}^{-}\right]$were also linear with non-zero intercepts, suggesting that the orders of reactions in $\left[\mathrm{OH}^{-}\right]$are less than unity. 


\subsection{Effect of Ionic Strength and Solvent Polarity}

The effect of ionic strength was studied by varying the concentration of $\mathrm{NaClO}_{4}$ in the reactions media at constant concentrations of permanganate, substrates and alkali. It was found that variation in ionic strength did not affect the rates as observed from the data listed in Table 1.

The solvent polarity of the reactions media, $\varepsilon$, was varied by varying the $t$-butyl alcohol-water content $(0-40 \%)$ in the reaction mixture with all other conditions being constant. The $\varepsilon$ values were calculated from the equation: $\varepsilon=\varepsilon_{\mathrm{w}} \mathrm{V}_{\mathrm{w}}+\varepsilon_{\mathrm{B}} \mathrm{V}_{\mathrm{B}}$, where $\varepsilon_{\mathrm{w}}$ and $\varepsilon_{\mathrm{B}}$ are solvent polarities of pure water and $t$ butyl alcohol, respectively, and $\mathrm{V}_{\mathrm{w}}$ and $\mathrm{V}_{\mathrm{B}}$ are the volume fractions of components water and $t$-butyl alcohol, respectively, in the total mixtures. The data clearly reveal that the decrease in solvent polarities of the solvent mixtures, i.e increase the $t$-butyl alcohol content did not alter the reaction rates.

Table 1. Effect of variation of $\left[\mathrm{MnO}_{4}^{-}\right],[\mathrm{S}],\left[\mathrm{OH}^{-}\right]$and I on the observed first order rate constants ( $k_{\text {obs }}$ ) in the oxidations of benzazolylformamidines by alkaline permanganate at $25^{\circ} \mathrm{C}$.

\begin{tabular}{|c|c|c|c|c|c|}
\hline \multirow{2}{*}{$10^{4}\left[\mathrm{MnO}_{4}^{-}\right]\left(\mathrm{mol} \mathrm{dm}^{-3}\right)$} & \multirow{2}{*}{$10^{2}[\mathrm{~S}]\left(\mathrm{mol} \mathrm{dm}^{-3}\right)$} & \multirow{2}{*}{$10^{2}\left[\mathrm{OH}^{-}\right]\left(\mathrm{mol} \mathrm{dm}^{-3}\right)$} & \multirow{2}{*}{$I\left(\mathrm{~mol} \mathrm{dm} \mathbf{~}^{-3}\right)$} & \multicolumn{2}{|c|}{$10^{5} k_{\text {obs }}\left(\mathrm{s}^{-1}\right)$} \\
\hline & & & & BIF & BTF \\
\hline 1.0 & 1.0 & 5.0 & 0.1 & 93.8 & 62.9 \\
\hline 2.0 & 1.0 & 5.0 & 0.1 & 97.4 & 64.0 \\
\hline 3.0 & 1.0 & 5.0 & 0.1 & 98.1 & 66.3 \\
\hline 4.0 & 1.0 & 5.0 & 0.1 & 97.2 & 65.4 \\
\hline 5.0 & 1.0 & 5.0 & 0.1 & 99.3 & 64.5 \\
\hline 6.0 & 1.0 & 5.0 & 0.1 & 100.2 & 67.9 \\
\hline 4.0 & 0.4 & 5.0 & 0.1 & 42.3 & 26.9 \\
\hline 4.0 & 0.6 & 5.0 & 0.1 & 62.9 & 39.1 \\
\hline 4.0 & 0.8 & 5.0 & 0.1 & 80.7 & 54.0 \\
\hline 4.0 & 1.0 & 5.0 & 0.1 & 97.2 & 65.4 \\
\hline 4.0 & 1.2 & 5.0 & 0.1 & 112.1 & 74.8 \\
\hline 4.0 & 1.4 & 5.0 & 0.1 & 126.3 & 85.1 \\
\hline 4.0 & 1.6 & 5.0 & 0.1 & 139.4 & 93.7 \\
\hline 4.0 & 1.0 & 4.0 & 0.1 & 84.0 & 58.2 \\
\hline 4.0 & 1.0 & 5.0 & 0.1 & 97.2 & 65.4 \\
\hline 4.0 & 1.0 & 6.0 & 0.1 & 109.9 & 78.3 \\
\hline 4.0 & 1.0 & 7.0 & 0.1 & 123.7 & 83.7 \\
\hline 4.0 & 1.0 & 8.0 & 0.1 & 135.9 & 90.8 \\
\hline 4.0 & 1.0 & 5.0 & 0.1 & 97.2 & 65.4 \\
\hline 4.0 & 1.0 & 5.0 & 0.2 & 101.3 & 66.1 \\
\hline 4.0 & 1.0 & 5.0 & 0.3 & 98.3 & 66.6 \\
\hline 4.0 & 1.0 & 5.0 & 0.4 & 98.7 & 64.2 \\
\hline 4.0 & 1.0 & 5.0 & 0.5 & 96.8 & 63.5 \\
\hline 4.0 & 1.0 & 5.0 & 0.6 & 99.7 & 67.5 \\
\hline 4.0 & 1.0 & 5.0 & 0.7 & 103.4 & 69.4 \\
\hline
\end{tabular}

Experimental error $\pm 4 \%$

\subsection{Effect of Temperature}

Table 2. Activation parameters of $k_{2}$ in the oxidations of benzazolylformamidines by alkaline permanganate. $[\mathrm{S}]=1.0 \times 10^{-2},\left[\mathrm{MnO}_{4}^{-}\right]$ $=4.0 \times 10^{-4},\left[\mathrm{OH}^{-}\right]=0.05$ and $I=0.1 \mathrm{~mol} \mathrm{dm}^{-3}$.

\begin{tabular}{|c|c|c|c|c|}
\hline Substrate & $\underset{1}{\Delta S^{f}} \mathrm{~J} \mathrm{~mol}^{-1} \mathrm{~K}^{-}$ & $\Delta H^{\ddagger,} \mathrm{kJ} \mathrm{mol}^{-1}$ & $\begin{array}{l}\Delta G^{\ddagger}{ }_{298}^{\prime} \mathrm{kJ} \\
\mathrm{mol}^{-1}\end{array}$ & $\begin{array}{l}E_{\mathrm{a}}{ }^{\neq}, \mathrm{kJ} \\
\mathrm{mol}^{-1}\end{array}$ \\
\hline BIF & -139.55 & 33.65 & 75.23 & 36.08 \\
\hline BTF & -125.40 & 35.83 & 73.20 & 37.25 \\
\hline
\end{tabular}

The rates of the reactions were carried out at five different temperatures $\left(20-40^{\circ} \mathrm{C}\right)$ at constant concentrations of the reactants and other conditions being constant. The results indicate that the rate constants were increased with raising temperature. The activation parameters of the second order rate constant $\left(k_{2}\right)$ are calculated using Eyring, Fig. 4a, and Arrhenius, Fig. 4b, plots and were listed in Table 2.

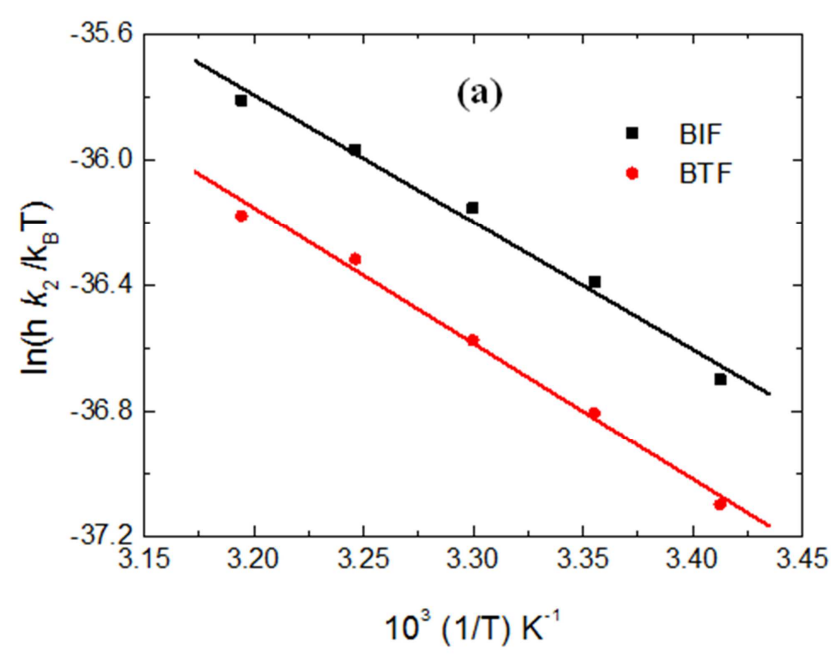




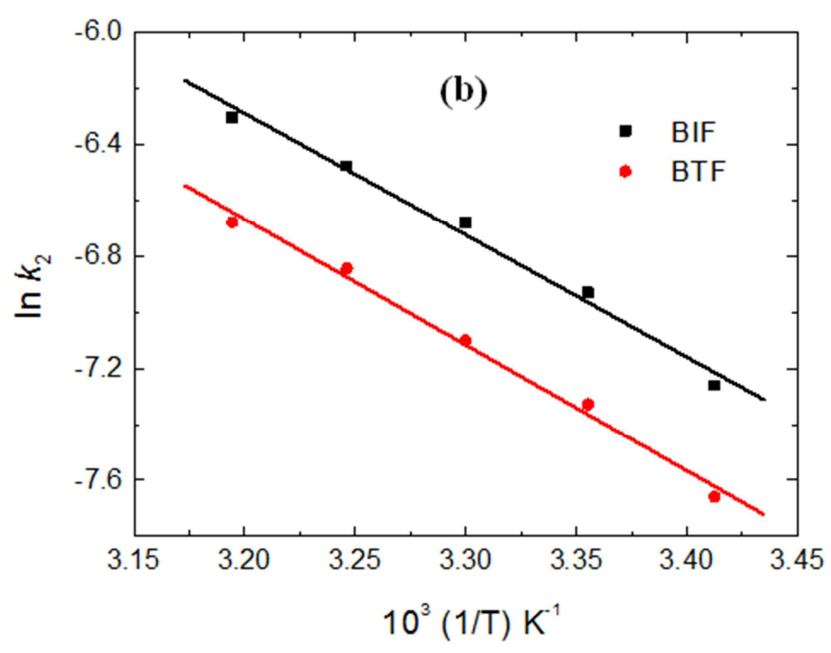

Figure 4. a) Eyring and, b) Arrhenius plots in the oxidations of benzazolylformamidines by alkaline permanganate. $[\mathrm{S}]=1.0 \times 10^{-2},\left[\mathrm{MnO}_{4}^{-}\right.$ ]$=4.0 \times 10^{-4},[\mathrm{OH}]=0.05$ and $I=0.1 \mathrm{~mol} \mathrm{dm}^{-3}$.

\subsection{Polymerization Study}

To test for the participation of the free radicals in these reactions, the reaction mixtures were mixed with known quantities of acrylonitrile monomer and kept for 6 hours under nitrogen. On dilution with methanol white precipitates were formed, indicating the participation of free radicals in the oxidation reactions. Blank experiments carried out with either permanganate or every substrate alone with acrylonitrile did not induce polymerization under the same experimental conditions.

\section{Discussion}

Permanganate ion is a powerful oxidant in aqueous alkaline media and exhibits various oxidation states, such as Mn(VII), $\mathrm{Mn}(\mathrm{V})$ and $\mathrm{Mn}(\mathrm{VI})$. Simandi et al. [29] reported that at $\mathrm{pH}>$ 12 , the reduction product of $\mathrm{Mn}(\mathrm{VII})$ is stable $\mathrm{Mn}(\mathrm{VI})$ and no further reduction is observed. The band that appear at $\lambda=606$ $\mathrm{nm}$ (Fig. 1) corresponds to $\mathrm{Mn}(\mathrm{VI})$ species [15, 29]. The formation of a manganate(VI) intermediate was also consistent with the green color observed as the reaction proceeded [30]. The appearance of two isosbestic points at wavelengths 575 and $473 \mathrm{~nm}$ during the courses of the reactions indicates the interconversion of $\mathrm{Mn}(\mathrm{VII})$ to both $\mathrm{Mn}(\mathrm{VI})$ and $\mathrm{Mn}(\mathrm{IV})$, as $\mathrm{MnO}_{2}$, respectively [31]. The yellow color persisted after completion of the oxidation reactions, then finally dispersed brown $\mathrm{MnO}_{2}$ sol, was observed, confirming that the $\mathrm{Mn}(\mathrm{V})$ species, hypomanganate(V), formed and subsequently decomposed to $\mathrm{Mn}(\mathrm{IV})$ sol. The latter was coagulated by aging to give a colloidal precipitate of $\mathrm{Mn}^{\mathrm{IV}} \mathrm{O}_{2}$. When the concentration of manganate(VI) intermediate builds up, a slow decay of the intermediate takes place to give rise to the final oxidation products.

It was reported $[32,33]$ that permanganate ion in aqueous alkaline media combines with alkali to form an alkalipermanganate species in a pre-equilibrium step, as described by equilibrium (3) in Scheme 1. This is consistent with the apparent order of less than unity in the alkali. The formation of $\left[\mathrm{MnO}_{4} \cdot \mathrm{OH}\right]^{2-}$ in alkaline medium in the present systems is further supported by the plots of $1 / k_{\mathrm{obs}}$ versus $1 /\left[\mathrm{OH}^{-}\right]$shown in Fig. 6, which were linear with non-zero intercepts.

Many investigators [17-25] have suggested that most of the oxidation reactions by permanganate ion in neutral and alkaline media proceed through intermediate complex formation between the oxidant and substrate. Spectroscopic evidence for such a complex was obtained from the UV-Vis spectra, Fig. 1. Also, the linearity of the plots between $1 / k_{\text {obs }}$ and $1 /[\mathrm{S}]$, Fig. 5, is considered as a kinetic evidence in favor of possible formation of a transient complex between oxidant and substrate similar to the well-known Michaelis-Menten mechanism [34] for enzyme-substrate reactions. On the other hand, the observed negligible effect of ionic strength and dielectric constant of the medium on the reaction rate implies the association of an ion and a neutral molecule [35, 36].

In view of the above arguments, the suggested reactions mechanism involves attack of the active species of permanganate, $\left[\mathrm{MnO}_{4} \cdot \mathrm{OH}\right]^{2-}$, on the reductant leading to the formation of a complex (C) in a prior equilibrium step. In this complex, one electron is transferred from the substrate to permanganate. Slow cleavage of the complex leads to the formation of a free radical intermediate derived from the substrate and manganate(VI) transient species. The intermediate radical is rapidly attacked by another alkalipermanganate species to yield an intermediate product. In a further fast step, the intermediate product is hydrolyzed to give the final oxidation products. The suggested mechanism is illustrated in the following sequence:

$$
\mathrm{MnO}_{4}^{-}+\mathrm{OH}^{-} \stackrel{K_{1}}{\rightleftharpoons}\left[\mathrm{MnO}_{4} \cdot \mathrm{OH}\right]^{2-}
$$

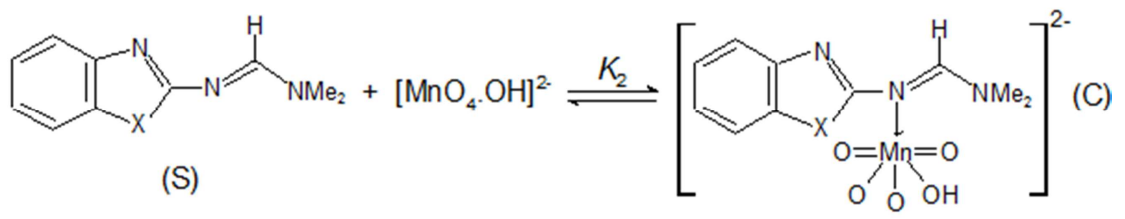

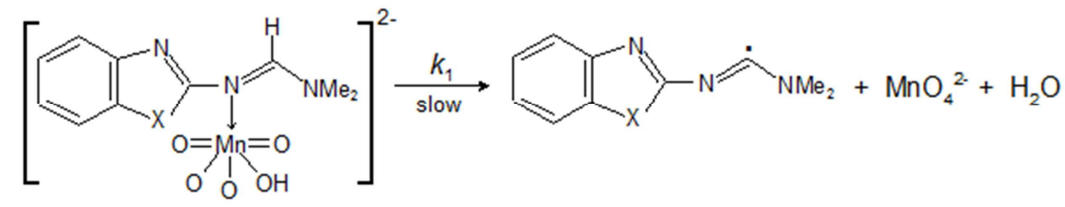




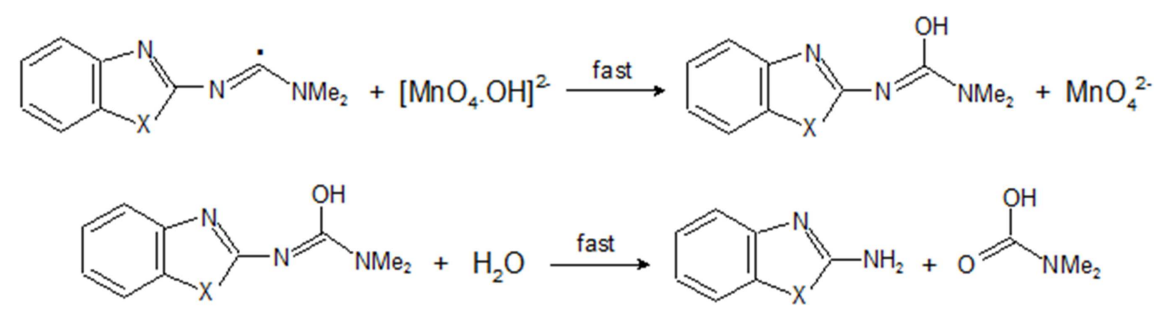

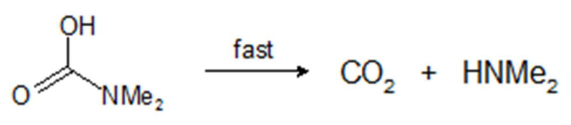

where $\mathrm{X}=\mathrm{NH}$ for $\mathrm{BIF}$ and $\mathrm{X}=\mathrm{S}$ for $\mathrm{BTF}$

Again, it has been reported [37] that the entropy of activation tends to be more negative for reactions of innersphere nature, whereas the reactions of positive $\Delta S^{\ddagger}$ values proceed via outer-sphere mechanism. The obtained large negative values of entropy of activation (Table 2) suggest that one-electron transfer of inner-sphere nature is the more plausible mechanism for the present oxidation reactions. On the other hand, the positive values of both $\Delta H^{\ddagger}$ and $\Delta G^{\ddagger}$ indicate that the complex formation is endothermic and nonspontaneous, respectively.

The relationship between reaction rate and substrate (S), hydroxyl ion and oxidant concentrations can be deduced (see Appendix A) to give the following rate law expression,

$$
\text { Rate }=\frac{\mathrm{k}_{1} \mathrm{~K}_{1} \mathrm{~K}_{2}[\mathrm{~S}]\left[\mathrm{OH}^{-}\right]\left[\mathrm{MnO}_{4}^{-}\right]}{1+\mathrm{K}_{1}\left[\mathrm{OH}^{-}\right]+\mathrm{K}_{1} \mathrm{~K}_{2}[\mathrm{~S}]\left[\mathrm{OH}^{-}\right]}
$$

Under pseudo-first order condition the rate law can be expressed by Eq. (10),

$$
\text { Rate }=\frac{-\mathrm{d}\left[\mathrm{MnO}_{4}^{-}\right]}{\mathrm{dt}}=k_{\mathrm{obs}}\left[\mathrm{MnO}_{4}^{-}\right]
$$

Comparing equations (9) and (10) and with rearrangement we obtain the following equations,

$$
\begin{gathered}
\frac{1}{\mathrm{k}_{\mathrm{obs}}}=\left(\frac{1+\mathrm{K}_{1}\left[\mathrm{OH}^{-}\right]}{\mathrm{k}_{1} \mathrm{~K}_{1} \mathrm{~K}_{2}\left[\mathrm{OH}^{-}\right]}\right) \frac{1}{[\mathrm{~S}]}+\frac{1}{\mathrm{k}_{1}} \\
\frac{1}{\mathrm{k}_{\mathrm{obs}}}=\left(\frac{1}{\mathrm{k}_{1} \mathrm{~K}_{1} \mathrm{~K}_{2}[\mathrm{~S}]}\right) \frac{1}{\left[\mathrm{OH}^{-}\right]}+\left(\frac{1}{\mathrm{k}_{1} \mathrm{~K}_{2}} \frac{1}{[\mathrm{~S}]}+\frac{1}{\mathrm{k}_{1}}\right)
\end{gathered}
$$

According to Eqs. (11) and (12), other conditions being constant, plots of $1 / k_{\mathrm{obs}}$ versus $1 /[\mathrm{S}]$ at constant $\left[\mathrm{OH}^{-}\right]$and $1 / k_{\text {obs }}$ versus $1 /\left[\mathrm{OH}^{-}\right]$at constant $[\mathrm{S}]$ should be linear with positive intercepts on the $1 / k_{\text {obs }}$ axes and are indeed found to be so as shown in Figs. 5 and 6, respectively.

The slopes and intercepts of such plots lead to calculation of the values of $k_{1}, K_{1}$ and $K_{2}$ as listed in Table 3. The obtained values of $K_{1}$ are in a good agreement with those reported in the literature [16-19].

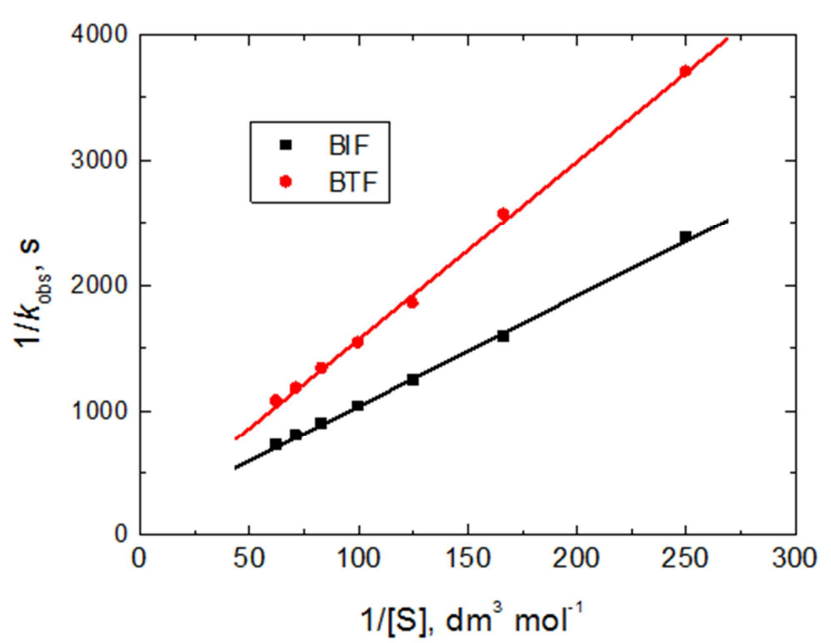

Figure 5. Verification of equation (9) for oxidations of benzazolylformamidines by alkaline permanganate. $\left[\mathrm{MnO}_{4}^{-}\right]=4.0 \times 10^{-4}$, $\left[\mathrm{OH}^{-}\right]=0.05$ and $\mathrm{I}=0.1 \mathrm{~mol} \mathrm{dm}^{-3}$ at $25^{\circ} \mathrm{C}$.

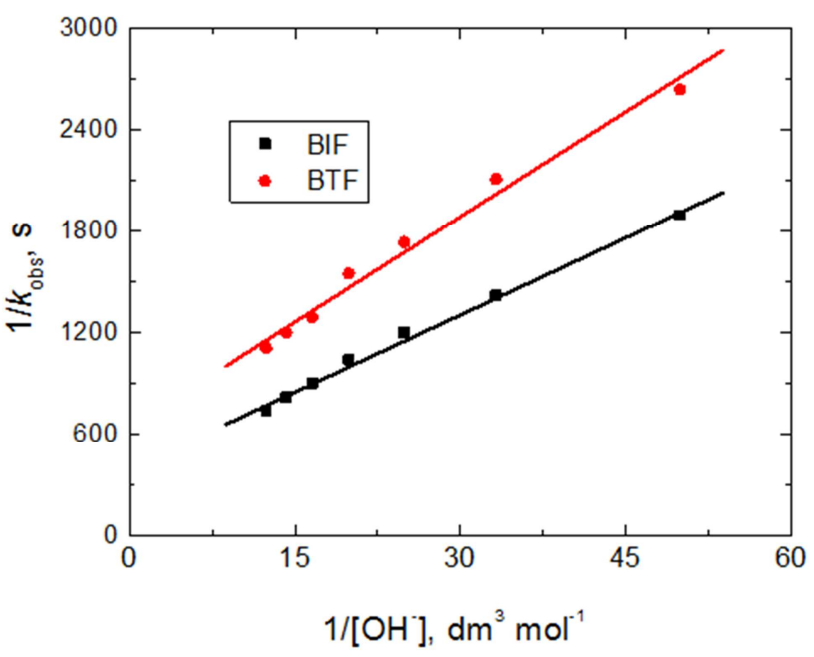

Figure 6. Verification of equation (10) for oxidations of benzazolylformamidines by alkaline permanganate. $[\mathrm{S}]=1.0 \times 10^{-2},\left[\mathrm{MnO}_{4}^{-}\right.$ $J=4.0 \times 10^{-4}$ and $I=0.1 \mathrm{~mol} \mathrm{dm}^{-3}$ at $25^{\circ} \mathrm{C}$.

Table 3. Values of $k_{1}, K_{1}$ and $K_{2}$ in the oxidations of benzazolylformamidines by alkaline permanganate. $[\mathrm{S}]=1.0 \times 10^{-2},\left[\mathrm{MnO}_{4}^{-}\right]=4.0 \times 10^{-4},\left[\mathrm{OH}^{-}\right]=0.05$ and $I=0.1 \mathrm{~mol} \mathrm{dm} \mathrm{m}^{-3}$ at $25^{\circ} \mathrm{C}$.

\begin{tabular}{llll}
\hline \multirow{2}{*}{ Substrate } & Constant & & \\
\cline { 2 - 4 } & $\mathbf{1 0}^{\mathbf{3}} \boldsymbol{k}_{\mathbf{1}}, \mathbf{s}^{-\mathbf{1}}$ & $\boldsymbol{K}_{\mathbf{1}}, \mathbf{d m}^{\mathbf{3}} \mathbf{~ m o l}^{-\mathbf{1}}$ & $\boldsymbol{K}_{\mathbf{2}}, \mathbf{d m}^{\mathbf{3}} \mathbf{~ m o l}^{-\mathbf{1}}$ \\
\hline BIF & 7.11 & 11.12 & 47.02 \\
BTF & 6.29 & 12.50 & 88.97 \\
\hline
\end{tabular}

Experimental error $\pm 4 \%$ 


\section{Conclusions}

The kinetics of oxidation of $N, \quad N$-dimethyl- $N$ '- $(1 H-$ benzimidazol-2-yl) formamidine (BIF) and $N, N$-dimethyl$N^{\prime}$-(benzthiazol-2-yl) formamidine (BTF) by alkaline permanganate has been studied spectrophotometrically. The final oxidation products of BIF and BTF were identified as 2aminobenzimidazole and 2-aminobenzthiazole, respectively, in addition to dimethylamine and carbon dioxide. Under comparable experimental conditions, the oxidation rate of BIF was found to be higher than that of BTF.

\section{Appendix A: Derivation of the Rate Law Expression}

According to suggested mechanism,

$$
\text { Rate }=\frac{-\mathrm{d}\left[\mathrm{MnO}_{4}^{-}\right]}{\mathrm{dt}}=k_{1}[\mathrm{C}]
$$

From reactions (3) and (4),

$$
K_{1}=\frac{\left[\mathrm{MnO}_{4} \cdot \mathrm{OH}^{2-}\right]}{\left[\mathrm{MnO}_{4}^{-}\right]\left[\mathrm{OH}^{-}\right]}
$$

Therefore,

$$
\begin{gathered}
{\left[\mathrm{MnO}_{4} \cdot \mathrm{OH}^{2-}\right]=K_{1}\left[\mathrm{MnO}_{4}^{-}\right]\left[\mathrm{OH}^{-}\right]} \\
K_{2}=\frac{[\mathrm{C}]}{[\mathrm{S}]\left[\mathrm{MnO}_{4} \cdot \mathrm{OH}^{2-}\right]} \\
\text { Thus, }[\mathrm{C}]=K_{2}[\mathrm{~S}]\left[\mathrm{MnO}_{4} \cdot \mathrm{OH}^{2-}\right]
\end{gathered}
$$

Substituting Eq. (A.3) into Eq. (A.5) leads to,

$$
[\mathrm{C}]=K_{1} K_{2}[\mathrm{~S}]\left[\mathrm{OH}^{-}\right]\left[\mathrm{MnO}_{4}{ }^{-}\right]
$$

Substituting Eq. (A.6) into Eq. (A.1) yields,

$$
\text { Rate }=k_{1} K_{1} K_{2}[\mathrm{~S}]\left[\mathrm{OH}^{-}\right]\left[\mathrm{MnO}_{4}^{-}\right]
$$

The total concentration of the substrate is given by,

$$
[\mathrm{S}]_{\mathrm{T}}=[\mathrm{S}]_{\mathrm{F}}+[\mathrm{C}]
$$

where $[\mathrm{S}]_{\mathrm{T}}$ and $[\mathrm{S}]_{\mathrm{F}}$ stand for total and free concentrations of the substrate.

Substituting Eq. (A.6) into Eq. (A.8) gives,

$$
\begin{aligned}
& {[\mathrm{S}]_{\mathrm{T}}=[\mathrm{S}]_{\mathrm{F}}+K_{1} K_{2}[\mathrm{~S}]\left[\mathrm{OH}^{-}\right]\left[\mathrm{MnO}_{4}^{-}\right]} \\
& {[\mathrm{S}]_{\mathrm{T}}=[\mathrm{S}]_{\mathrm{F}}\left(1+K_{1} K_{2}\left[\mathrm{OH}^{-}\right]\left[\mathrm{MnO}_{4}^{-}\right]\right)}
\end{aligned}
$$

Therefore,

$$
[\mathrm{S}]_{\mathrm{F}}=\frac{[\mathrm{S}]_{\mathrm{T}}}{1+\mathrm{K}_{1} \mathrm{~K}_{2}\left[\mathrm{OH}^{-}\right]\left[\mathrm{MnO}_{4}^{-}\right]}
$$

Similarly,

$$
\left[\mathrm{MnO}_{4}^{-}\right]_{\mathrm{T}}=\left[\mathrm{MnO}_{4}^{-}\right]_{\mathrm{F}}+\left[\mathrm{MnO}_{4} \cdot \mathrm{OH}^{2-}\right]+[\mathrm{C}]
$$

Substituting Eqs. (A.3) and (A6) into Eq. (A.12) gives,

$\left[\mathrm{MnO}_{4}^{-}\right]_{\mathrm{T}}=\left[\mathrm{MnO}_{4}^{-}\right]_{\mathrm{F}}\left(1+K_{1}\left[\mathrm{OH}^{-}\right]+K_{1} K_{2}[\mathrm{~S}]\left[\mathrm{OH}^{-}\right]\left[\mathrm{MnO}_{4}^{-}\right]\right)(\mathrm{A} .13)$

$$
\left[\mathrm{MnO}_{4}^{-}\right]_{\mathrm{F}}=\frac{\left[\mathrm{MnO}_{4}^{-}\right]_{\mathrm{T}}}{1+\mathrm{K}_{1}\left[\mathrm{OH}^{-}\right]+\mathrm{K}_{1} \mathrm{~K}_{2}[\mathrm{~S}]\left[\mathrm{OH}^{-}\right]}
$$

Also,

$$
\begin{array}{r}
{\left[\mathrm{OH}^{-}\right]_{\mathrm{T}}=\left[\mathrm{OH}^{-}\right]_{\mathrm{F}}+\left[\mathrm{MnO}_{4} \cdot \mathrm{OH}^{2-}\right]} \\
{\left[\mathrm{OH}^{-}\right]_{\mathrm{F}}=\frac{\left[\mathrm{OH}^{-}\right]_{\mathrm{T}}}{1+\mathrm{K}_{1}\left[\mathrm{MnO}_{4}^{-}\right]}}
\end{array}
$$

Substituting Eqs. (A.11), (A.14) and (A.16) into Eq. (A.7) (and omitting ' $\mathrm{T}$ ' and ' $\mathrm{F}$ ' subscripts) we get,

$$
\text { Rate }=\frac{\mathrm{k}_{1} \mathrm{~K}_{1} \mathrm{~K}_{2}[\mathrm{~S}]\left[\mathrm{OH}^{-}\right]\left[\mathrm{MnO}_{4}^{-}\right]}{\left(1+\mathrm{K}_{1} \mathrm{~K}_{2}\left[\mathrm{OH}^{-}\right]\left[\mathrm{MnO}_{4}^{-}\right]\right)\left(1+\mathrm{K}_{1}\left[\mathrm{MnO}_{4}^{-}\right]\right)\left(1+\mathrm{K}_{1}\left[\mathrm{OH}^{-}\right]+\mathrm{K}_{1} \mathrm{~K}_{2}[\mathrm{~S}]\left[\mathrm{OH}^{-}\right]\right)}
$$

In view of low concentration of $\left[\mathrm{MnO}_{4}{ }^{-}\right]$used, both first and second terms in the denominator of Eq. (A.17) approximate to unity. Therefore, Eq. (A.17) becomes,

$$
\text { Rate }=\frac{\mathrm{k}_{1} \mathrm{~K}_{1} \mathrm{~K}_{2}[\mathrm{~S}]\left[\mathrm{OH}^{-}\right]\left[\mathrm{MnO}_{4}^{-}\right]}{1+\mathrm{K}_{1}\left[\mathrm{OH}^{-}\right]+\mathrm{K}_{1} \mathrm{~K}_{2}[\mathrm{~S}]\left[\mathrm{OH}^{-}\right]}
$$

Under pseudo-first order conditions, the rate-law can be expressed as,

$$
\text { Rate }=\frac{-\mathrm{d}\left[\mathrm{MnO}_{4}^{-}\right]}{\mathrm{dt}}=k_{\mathrm{obs}}\left[\mathrm{MnO}_{4}^{-}\right]
$$

Comparing Eqs. (A.18) and (A.19), the following relationship is obtained,

$$
k_{\mathrm{obs}}=\frac{\mathrm{k}_{1} \mathrm{~K}_{1} \mathrm{~K}_{2}[\mathrm{~S}]\left[\mathrm{OH}^{-}\right]}{1+\mathrm{K}_{1}\left[\mathrm{OH}^{-}\right]+\mathrm{K}_{1} \mathrm{~K}_{2}[\mathrm{~S}]\left[\mathrm{OH}^{-}\right]}
$$

and with rearrangement, the following equations are obtained,

$$
\begin{gathered}
\frac{1}{\mathrm{k}_{\mathrm{obs}}}=\left(\frac{1+\mathrm{K}_{1}\left[\mathrm{OH}^{-}\right]}{\mathrm{k}_{1} \mathrm{~K}_{1} \mathrm{~K}_{2}\left[\mathrm{OH}^{-}\right]}\right) \frac{1}{[\mathrm{~S}]}+\frac{1}{\mathrm{k}_{1}} \\
\frac{1}{\mathrm{k}_{\mathrm{obs}}}=\left(\frac{1}{\mathrm{k}_{1} \mathrm{~K}_{1} \mathrm{~K}_{2}[\mathrm{~S}]}\right) \frac{1}{\left[\mathrm{OH}^{-}\right]}+\left(\frac{1}{\mathrm{k}_{1} \mathrm{~K}_{2}} \frac{1}{[\mathrm{~S}]}+\frac{1}{\mathrm{k}_{1}}\right)
\end{gathered}
$$




\section{References}

[1] Keri RS, Patil MR, Patil SA, Budagumpi S (2015) A comprehensive review in current developments of benzothiazole based molecules in medicinal chemistry. Eur. J. Med. Chem., 89: 207-251.

[2] Abdul Rouf CT (2014) Bioactive thiazole and benzothiazole derivatives. Eur. J. Med. Chem., 1-17.

[3] Hisamoddin SZK, Priyanka S, Yogesh SP, Patel Nilam PU (2014) Benzothiazole the molecule of diverse biological activities. Pharma Sci. Monitor, 5: 207-225.

[4] Shi B, Chen R, Huang Y (2004) Synthesis of N-(benzothiazol2-yl-aminodialkyl)-thiophosphate. Gaodeng Xuexiao Huaxue Xuebao, 25: 1458-1460.

[5] Huang ST, Hsei LJ, Chen C (2006) Synthesis and anticancer evaluation of bis(-benzimidazoles), bis(benzoxazoles), and benzothiazoles, Bioorg. Med. Chem., 14: 6106-6119.

[6] Kamal A, Kumar BA, Arifuddin M, Dastidar SG (2006) Synthesis and biological activity of new $4 \beta-N$-heteroaryl analogues of podophyllo. Lett. Drug Design. Dis., 3: 205-209.

[7] Yongseog Ch, Young-Kook Sh, Chang-Guo Z, Sungduck L, Hoon Ch (2004) Synthesis and evaluation of antitumor activity of 2- and 6-[(1, 3-benzothiazol-2-yl) aminomethyl]-5, 8-dimethoxy-1, 4-naphthoquinone derivatives, Arch. Pharm. Res. 27: 893-890.

[8] Singh SP, Segal S (1988) Study of fungicidal activities of some benzothiazoles, Ind. J. Chem., 27B: 941-943.

[9] Suresh CH, Rao JH, Jayaveera KN, Subudhi SK (2013) Synthesis and anthelmintic activity of 3-(2-hydrozino benzothiazole)-substituted indole-2-one. Int. J. Pharm., 2: 257261.

[10] Akhtar T, Hameed S, Al-Masoudi N, Loddo R, Colla P (2008) In vitro antitumor and antiviral activities of new benzothiazole and 1, 3, 4-oxadiazole-2-thione derivatives. Acta Pharm., 58: $135-149$.

[11] Abdel-Rahman HM, Morsy MA (2007) Novel benzothiazolyl urea and thiourea derivatives with potential cytotoxic and antimicrobial activities. J. Enz. Inh. Med. Chem., 22: 57-64.

[12] Abdel-Zaher A, Elassar A (2015) Synthesis of benzoazolyl-N, N-dimethylformamidines: complexation and biological activity. Eur. Int. J. Sci. Technol., 4: 88-99.

[13] Arnold DI, Cotton FA, Matonic JH, Murillo SA (1997) Poly[di- $\mu 3$-nicotinato-hemi- $\mu 4$-oxalato-hemi- $\mu 2$-oxalatoneodymium(III) silver(I)] dehydrate, Polyhedron, 16: 1837 1844 .

[14] Mitzi DB, Liang K (1997) Synthesis, resistivity, and thermal properties of the cubic perovskite $\mathrm{NH}_{2} \mathrm{CH}=\mathrm{NH}_{2} \mathrm{SnI}_{3}$ and related systems, J. Solid State Chem., 134: 376-382.

[15] Stewart R (1965) Oxidation in Organic Chemistry, Part A (ed.) Wiberg KB, New York, Academic Press.

[16] Jose TP, Nandibewoor ST, Tuwar SM (2005) Mechanism of oxidation of L-histidine by heptavalent manganese in alkaline medium. E-J. Chem., 2: 75-85.

[17] A. Fawzy, S. S. Ashour, M. A. Musleh, Base-catalyzed oxidation of L-asparagine by alkaline permanganate and the effect of alkali-metal ion catalysts: kinetics and mechanistic approach, React. Kinet. Mech. Catal., 111 (2014) 443-460.

[18] Fawzy A, Shaaban MR (2014) Kinetic and mechanistic investigations on the oxidation of N'-heteroaryl unsymmetrical formamidines by permanganate in aqueous alkaline medium. Transition Met. Chem. 39: 379-386.

[19] Fawzy A, Zaafarany IA, Alfahemi J, Tirkistani FA (2015) Base-catalyzed oxidation of aminotriazole derivative by permanganate ion in aqueous alkaline medium: a kinetic study. Int. J. Inn. Res. Sci. Eng. Tech., 4: 6802-6814.

[20] Asghar BH, Fawzy A (2014) Kinetic, mechanistic, and spectroscopic studies of permanganate oxidation of azinylformamidines in acidic medium, with autocatalytic behavior of manganese(II). J. Saudi Chem. Soc., in press.

[21] Fawzy A, Ashour SS, Musleh MA (2014) Kinetics and mechanism of oxidation of L-histidine by permanganate ions in sulfuric acid medium. Int. J. Chem. Kinet. 46: 370-381.

[22] Ahmed GA, Fawzy A, Hassan RM (2007) Spectrophotometric evidence for the formation of short-lived hypomanganate $(\mathrm{V})$ and manganate(VI) transient species during the oxidation of $K$-carrageenan by alkaline permanganate. Carbohydr. Res., 342: 1382-1386.

[23] Zaafarany IA, Fawzy A, Ahmed GA, Ibrahim SA, Hassan RM, Takagi HD (2010) Further evidence for detection of short-lived transient hypomanganate(V) and manganate(VI) intermediates during oxidation of some sulfated polysaccharides by alkaline permanganate using conventional spectrophotometeric techniques. Carbohydr. Res., 345: 15881593.

[24] Hassan RM, Fawzy A, Alarifi A, Ahmed GA, Zaafarany IA, Takagi HD (2011) Base-catalyzed oxidation of some sulfated macromolecules: kinetics and mechanism of formation of intermediate complexes of short-lived manganate (VI) and/or hypomanganate $(\mathrm{V})$ during oxidation of iota- and lambdacarrageenan polysaccharides by alkaline permanganate. J. Mol. Catal. A, 335: 38-45.

[25] Hassan RM, Dahy A, Ibrahim S, Zaafarany IA, Fawzy A (2012) Oxidation of some macromolecules. Kinetics and mechanism of oxidation of methyl cellulose polysaccharide by permanganate ion in acid perchlorate solutions. Ind. Eng. Chem. Res., 51: 5424-5432.

[26] Gardner KA, Kuehnert LL, Mayer JM (1997) Hydrogen atom abstraction by permanganate: oxidations of arylalkanes in organic solvents. Inorg. Chem., 36: 2069-2078.

[27] Vogel AI (1973) Text book of practical organic chemistry including quantitative organic analysis, 3rd edn, $332 \mathrm{pp}$. ELBS, Longman.

[28] Feigl F (1975) Spot tests in organic analysis, 195 pp. Elsevier, New York.

[29] Simandi KI, Jaky M, Schelly ZA (1984) Short-lived manganate $(\mathrm{VI})$ and manganate $(\mathrm{V})$ intermediates in the permanganate oxidation of sulfite ion, J. Am. Chem. Soc., 106: 6866-6867; Simandi LI, Jaky M, Savage CR, Schelly ZA (1985) Kinetics and mechanism of the permanganate ion oxidation of sulfite in alkaline solutions. The nature of shortlived Intermediates, J. Am. Chem. Soc., 107: 4220-4224.

[30] Cotton FA, Wilkinson G (1980) Advanced Inorganic Chemistry, pp 747, John Wiley and Sons, New York. 
[31] Hassan RM (1993) Alginate polyelectrolyte ionotropic gels. XIV. Kinetics and mechanism of formation of intermediate complex during the oxidation of alginate polysaccharide by alkaline permanganate with a spectrophotometric evidence of manganate(VI) transient species. J. Polym. Sci. A, 31: 51-59.

[32] Panari RG, Chougale RB, Nandibewoor ST (1998) Oxidation of mandelic acid by alkaline potassium permanganate. A kinetic study, J. Phys. Org. Chem., 11: 448-454.

[33] De Oliveira LA, Toma HE, Giesbrecht E (1976) Kinetics of oxidation of free and coordinated dimethylsulfoxide with permanganate in aqueous solution, Inorg. Nucl. Chem. Lett., 2: $195-203$.
[34] Michaelis L, Menten ML (1913) The kinetics of invertase action. Biochem. Z. 49: 333-369.

[35] Frost AA, Person RG (1973) Kinetics and Mechanism, 147 pp. Wiley Eastern, New Delhi; Amis ES (1966) Solvent effect on reaction rates and mechanism, pp. 28, Academic Press, New York.

[36] Laidler K (1965) Chemical Kinetics. pp 123, McGraw-Hill, New York.

[37] Hicks KW, Toppen DL, Linck RG (1972) Inner-sphere electron-transfer reactions of vanadium(II) with azidoamine complexes of cobalt(III). Inorg. Chem. 11: 310-315. 